\title{
Tanshinone IIA enhances chemosensitivity of colon cancer cells by suppressing nuclear factor- $\kappa B$
}

\author{
YANGQIU BAI, LIDA ZHANG, XINHUI FANG and YUXIU YANG \\ Department of Gastroenterology, Henan Provincial People's Hospital, \\ Zhengzhou University, Zhengzhou, Henan 450003, P.R. China
}

Received September 22, 2014; Accepted July 28, 2015

DOI: $10.3892 /$ etm.2016.2984

\begin{abstract}
The aim of the present study was to investigate the effect and molecular mechanism of tanshinone IIA (TSA) on colon cancer cells. Cell viability was determined using Cell Counting kit- 8 assay and the results demonstrated that TSA treatment significantly decreased the cell viability of HCT1116 and COLO205 cells in a dose-dependent manner. TSA treatment also sensitized HCT1116 and COLO205 cells to fluorouracil therapy in a concentration-dependent manner. Western blotting was performed in order to investigate the molecular mechanisms of TSA action and determine the level of phosporylated p65 and nuclear factor- $\kappa \mathrm{B}(\mathrm{NF}-\kappa \mathrm{B})$-regulated genes, including vascular endothelial growth factor (VEGF), c-Myc, cyclooxygenase-2 (COX-2) and B-cell lymphoma-2 (Bcl-2). The results revealed that TSA treatment greatly decreased the level of phosphorylated p65 in the nucleus, which indicated the inhibition of NF- $\kappa \mathrm{B}$ activation by TSA treatment. TSA also decreased the expression levels of VEGF, c-Myc, COX-2 and $\mathrm{Bcl}-2$. Furthermore, the inhibition of $\mathrm{NF}-\kappa \mathrm{B}$ activation with the specific inhibitor, pyrrolidine dithiocarbamate, increased the induction of cell death and chemosensitization effect of TSA in colon cancer cells. In conclusion, these results suggest that TSA induces cell death and chemosensitizes colon cancer cells through the suppression of $\mathrm{NF}-\kappa \mathrm{B}$ signaling.
\end{abstract}

\section{Introduction}

Colorectal cancer is the third most common type of human cancer and a major global public health concern (1). The incidence rate of colorectal cancer has been increasing in the Chinese population; in Beijing, the annual incidence of CRC has increased from 16 per 100,000 to 24 per 100,000 in the past decade (2). Chemoprevention, including the use of oxaliplatin, fluorouracil and leucovorin, is considered to be the

Correspondence to: Professor Yuxiu Yang, Department of Gastroenterology, Henan Provincial People's Hospital, 7 Weiwu Road, Zhengzhou University, Zhengzhou, Henan 450003, P.R. China E-mail: yangyuxiu668@163.com

Key words: tanshinone IIA, chemosensitization, cell death, nuclear factor- $\kappa \mathrm{B}$, colon cancer most promising strategy, since other therapies fail to control gastrointestinal cancers (3). However, at present, no optimal adjuvant chemotherapy exists; therefore, there is a constant requirement for the development of rationally designed, novel adjuvant therapeutic strategies for the treartment of colon cancer. In the past few decades, traditional Chinese herbal medicines have become a widely accepted treatment option for colorectal cancer and an increasing number of studies have focused on the identification of new bioactive pure compounds and herbs (4,5). Danshen, also known as Radix Salviae miltiorrhiza, is widely prescribed in traditional Chinese medicine for the treatment of cardiovascular diseases $(6,7)$. Tanshinone IIA (TSA; $\mathrm{C}_{19} \mathrm{H}_{18} \mathrm{O}_{3}$ ) is extracted from Danshen $(8,9)$ and presents anti-inflammatory $(10,11)$ and antioxidant properties $(12,13)$. Recently, TSA has been proven to also harbor antitumor activities in various human malignant neoplasms (14-17). $\mathrm{Su}$ et al reported that TSA may inhibit cell growth and induce apoptosis in colon cancer (18); however, the molecular mechanisms of TSA action remain unclear. In the present study, the influence and molecular mechanism of TSA on colon cancer cell growth and chemosensitivity of colon cancer cells to fluorouracil (5-FU) were investigated.

\section{Materials and methods}

Cell culture and materials. HCT1116 and COLO205 colon cancer cells were purchased from American Type Culture Collection (Manassas, VA, USA). The cells were cultured in RPMI-1640 medium (Gibco-BRL, Gasthersburg, MD, USA) supplemented with $10 \%$ heat-inactivated fetal bovine serum (Gibco-BRL) and 2\% penicillin/streptomycin (penicillin, $10,000 \mathrm{U} / \mathrm{ml}$; streptomycin, $10 \mathrm{mg} / \mathrm{ml}$ ). The cells were placed into tissue culture flasks $\left(75 \mathrm{~cm}^{2}, 250 \mathrm{ml}\right)$ and grown at $37^{\circ} \mathrm{C}$ in humidified atmosphere consisting of $5 \% \mathrm{CO}_{2}$ and $95 \%$ air. TSA was purchased from Dasherb Corp. (Shenyang, China). Aprotinin and leupeptin were obtained from Sigma-Aldrich (St. Louis, MO, USA). Dimethyl sulfoxide was purchased from EMD Millipore Corporation (Darmstadt, Germany). The antibodies used in the present study were the following: Mouse monoclonal anti-actin (1:1,000; cat. no. sc-8432; Santa Cruz Biotechnology Inc., Santa Cruz, CA, USA), rabbit polyclonal anti-vascular endothelial growth factor (VEGF; 1:500; cat. no. ab46154; Abcam, Cambridge, MA, USA), rabbit polyclonal anti-c-Myc (1:1,000; cat. no. 9402S; Cell Signaling 
Technology, Inc., Denvers, MA USA), mouse monoclonal anti-cyclooxygenase-2 (COX2; 1:1,000; cat. no. sc-376861) and rabbit polyclonal anti-B-cell lymphoma-2 (Bcl-2; 1:2,000; cat. no. sc-492) (both from Santa Cruz Biotechnology Inc.).

Cell viability assay. Cell viability was measured using a Cell Counting kit (CCK)-8 kit (Dojindo Molecular Technologies, Inc., Kumamoto, Japan). Briefly, cells were seeded in a 94-well plate at a density of $2 \times 10^{4}$ cells per well in $200 \mu \mathrm{l}$ culture medium. The following day the cells were incubated with drug for $48 \mathrm{~h}$. At the end of the experiment, $20 \mu \mathrm{l}$ CCK-8 solution was added to the cells. The cells were then further incubated at $37^{\circ} \mathrm{C}$ for $2 \mathrm{~h}$. Subsequently, the optical density (OD) at $450 \mathrm{~nm}$ was measured using a VICTOR ${ }^{\mathrm{TM}}$ X Multi-Label reader (PerkinElmer, Inc., Waltham, MA, USA) and the percentage of cell viability was calculated as $\mathrm{OD}_{\text {drug }} / \mathrm{OD}_{\text {control }} \times 100 \%$.

Preparation of nuclear extract. Following treatment, the cells were harvested and washed twice with ice-cold phosphate-buffered saline (PBS). Next, the cell samples were resuspended in $1 \mathrm{ml}$ PBS and nuclear extracts were prepared on ice as described in a previous study (19). Following centrifugation at $15,000 \times \mathrm{g}$ for $10 \mathrm{~min}$ at $4^{\circ} \mathrm{C}$, the cell pellet was suspended in an ice-cold buffer (consisting of $10 \mathrm{mmol} / \mathrm{l}$ HEPES, $1.5 \mathrm{mmol} / 1 \mathrm{MgCl}_{2}, 0.5 \mathrm{mmol} / 1$ dithiothreitol, $0.2 \mathrm{mmol} / \mathrm{l}$ phenylmethylsulphonylfluoride and $0.2 \mathrm{mmol} / \mathrm{l}$ $\mathrm{KCl}$ ), vortexed for $10 \mathrm{sec}$ and centrifuged at $15,000 \mathrm{x} \mathrm{g}$ for $5 \mathrm{~min}$ at $4^{\circ} \mathrm{C}$. Subsequently, the nuclear pellet was washed in $1 \mathrm{ml}$ buffer (consisting of $20 \mathrm{mmol} / \mathrm{l} \mathrm{HEPES}, 25 \%$ glycerol, $0.2 \mathrm{mmol} / 1$ ethylenediaminetetraacetic acid, $1.5 \mathrm{mmol} / \mathrm{l}$ $\mathrm{MgCl}_{2}$ and $0.42 \mathrm{~mol} / 1$ hypertonic saline), resuspended in $30 \mathrm{ml}$ buffer (20 mmol/1 HEPES, $25 \%$ glycerol, $0.42 \mathrm{~mol} / \mathrm{l}$ $\left.\mathrm{NaCl}, 1.5 \mathrm{mmol} / 1 \mathrm{MgCl}_{2}, 0.2 \mathrm{mmol} / \mathrm{l} \mathrm{EDTA}\right)$, rotated for $30 \mathrm{~min}$ at $4^{\circ} \mathrm{C}$ and centrifuged at $14,500 \mathrm{x} \mathrm{g}$ for $20 \mathrm{~min}$ at $4^{\circ} \mathrm{C}$. Finally, the supernatants were used as nuclear extracts.

Western blotting. Whole cell lysates or nuclear extracts were separated using $12 \%$ SDS-PAGE, as described previously (20). Transfer buffer [25 mM Tris (pH 8.5), 20\% methanol and $0.2 \mathrm{M}$ glycine] was used to equilibrate the separated proteins, which were then transferred onto a $0.4-\mu$ m polyvinylidene fluoride membrane (EMD Millipore Corporation, Bedford, MA, USA). The membranes were incubated with $5 \%$ non-fat dry milk in Tris-buffered saline containing $0.1 \%$ Tween- 20 for $1 \mathrm{~h}$, followed by washing and then incubation with appropriate dilutions of specific primary antibodies at $4^{\circ} \mathrm{C}$ overnight. Following incubation with secondary anti-mouse peroxidase-conjugated antibody (dilution, 1:15,000; Sigma-Aldrich), the immune-reactive bands were visualized using an enhanced chemiluminescence detection kit (EMD Millipore Corporation, Darmstadt, Germany). $\beta$-actin was used as an internal control for western blotting.

Statistical analysis. The statistical analysis was performed using SPSS 17.0 software (SPSS Inc., Chicago, IL, USA) and are presented as the mean \pm standard deviation. One-way analysis of variance was performed to compare numeric variables between groups. $\mathrm{P}<0.05$ was considered to indicate a statistically significant difference.

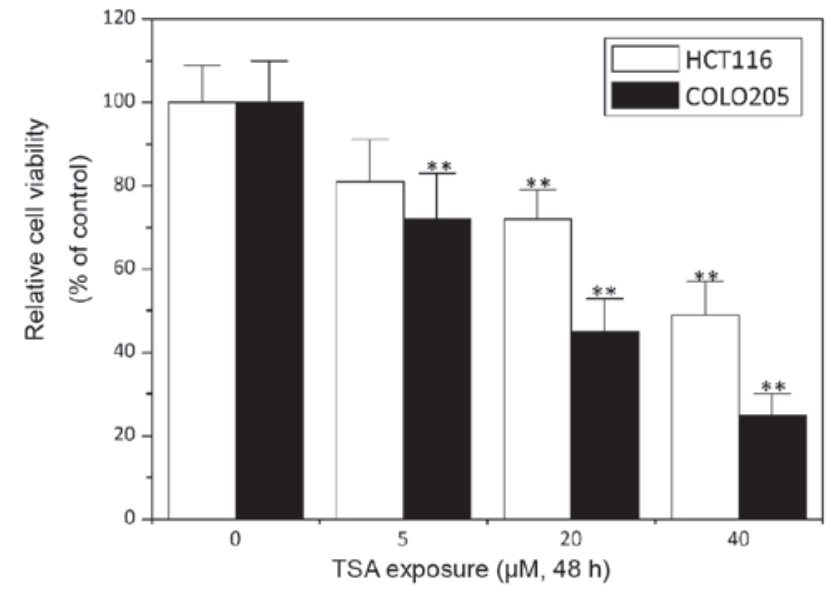

Figure 1. TSA induced cell death in the COLO205 and HCT1116 colon cancer cell lines. Cultured cells $\left(2 \times 10^{4}\right.$ cells per well) were treated with different concentrations (5-40 $\mu \mathrm{M})$ of TSA for $48 \mathrm{~h}$. Cell viability was determined using Cell Counting kit- 8 and presented as a percentage of the control value. Data are presented as the mean \pm standard deviation of five independent experiments. ${ }^{* *} \mathrm{P}<0.05$ vs. the respective control group. TSA, tanshinone IIA.

\section{Results}

Effect of TSA on cell viability of colon cancer cells. TSA has been demonstrated to exert an antitumor activity in numerous types of human cancer, including breast, lung, liver, prostate and ovarian cancer and leukemia $(15,21-25)$. The data of the present study showed that the exposure of the HCT1116 and COLO205 colon cancer cell lines to TSA greatly decreased their cell viability in a concentration-dependent manner $(\mathrm{P}<0.05$; Fig. 1), which suggested an antitumor effect of TSA in colon cancer.

TSA enhances chemosensitivity of colon cancer cells. Drug resistance is a clinical challenge that can result in the failure of colon cancer therapy (26). In order to examine how TSA influences the sensitivity of colon cancer cells to chemotherapy, 5-FU chemotherapy was combined with TSA treatment. As shown in Fig. 2, 5-FU-induced cell death in HCT1116 and COLO205 cells was considerably enhanced by $20 \mu \mathrm{M}$ TSA treatment $(\mathrm{P}<0.05)$, which suggested that TSA was able to potentiate the chemosensitivity of colon cancer cells.

Involvement of nuclear factor- $\kappa B(N F-\kappa B)$ in TSA activity. As shown by the aforementioned data, TSA can decrease cell viability and increase the chemosensitivity of colon cancer cells; however, the molecular mechanisms of TSA action remain to be elucidated. In order to further investigate the mechanisms of TSA action, the influence of TSA on the activation of NF- $\kappa B$ was determined, since it has been suggested that NF- $\mathrm{B}$ is involved in the development and progression of various malignant neoplasms (27-33), which made it a target for tumor therapeutics $(34,35)$. The present data revealed that $20 \mu \mathrm{M}$ TSA treatment significantly decreased the level of phosphorylation of p65, a subunit of NF- $\mathrm{KB}$ (Fig. 3A), which indicated the inhibitory effect of TSA on NF- $\mathrm{kB}$ activation. In addition, the expression of NF- $\mathrm{kB}$ regulated genes was examined. As illustrated in Fig. 3B, $20 \mu \mathrm{M}$ TSA was able to considerably decrease VEGF, c-Myc, COX-2 and Bcl-2 expression. 

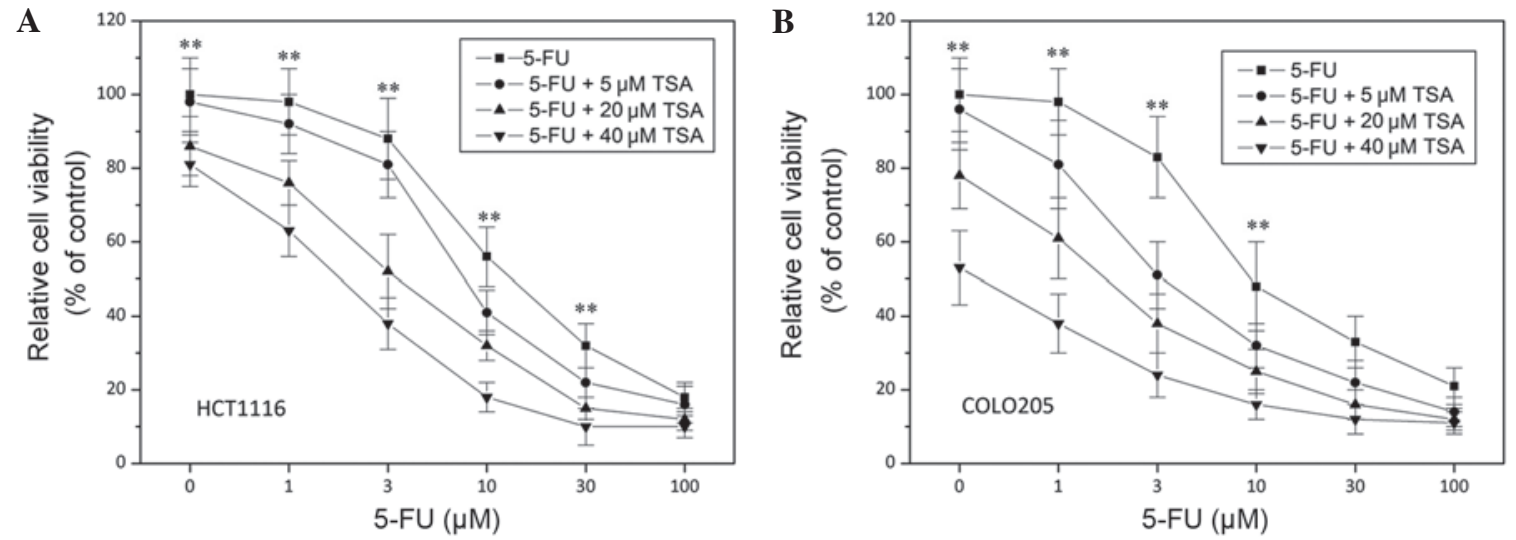

Figure 2. TSA enhances cytotoxicity of 5-FU in (A) HCT1116 and (B) COLO205 colon cancer cell lines. Colon cancer cells were treated with different doses of 5-FU $(0-100 \mu \mathrm{M})$, with or without different concentrations of TSA $(0-40 \mu \mathrm{M})$ for $24 \mathrm{~h}$. Cell viability was measured using Cell Counting kit-8 and presented as a percentage of the control values. Data are presented as the mean \pm standard deviation of five independent experiments. ${ }^{* *} \mathrm{P}<0.05,20 \mu \mathrm{M}$ and $40 \mu \mathrm{M}$ TSA + 5-FU group vs. 5-FU group. TSA, tanshinone IIA; 5-FU, fluorouracil.

A

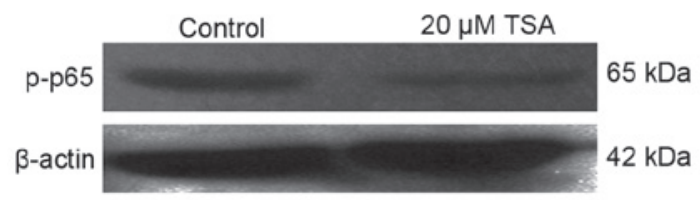

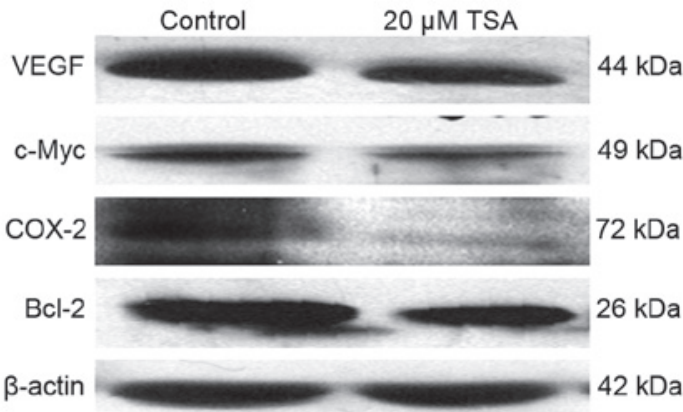

Figure 3. Effect of TSA on the activation of NF-kB and the expression of its downstream gene products. (A) TSA inhibited the phosphorylation of p65, which is a subunit of NF-kB. COLO205 cells were treated with $20 \mu \mathrm{M}$ TSA for $48 \mathrm{~h}$. Cells were harvested and the expression of phosphorylated-p65 in their nucleus was evaluated using western blotting. (B) TSA downregulated the downstream gene products of NF- $\mathrm{kB}$ in COLO205 cells. After $48 \mathrm{~h}$ of incubation, the levels of VEGF, c-Myc, COX-2 and Bcl-2 were determined using western blotting. $\beta$-actin was used as an internal control. A representative example from three independent experi-

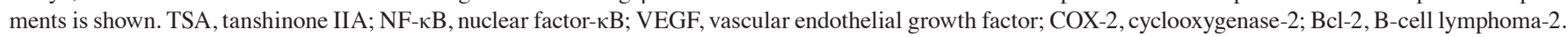

A

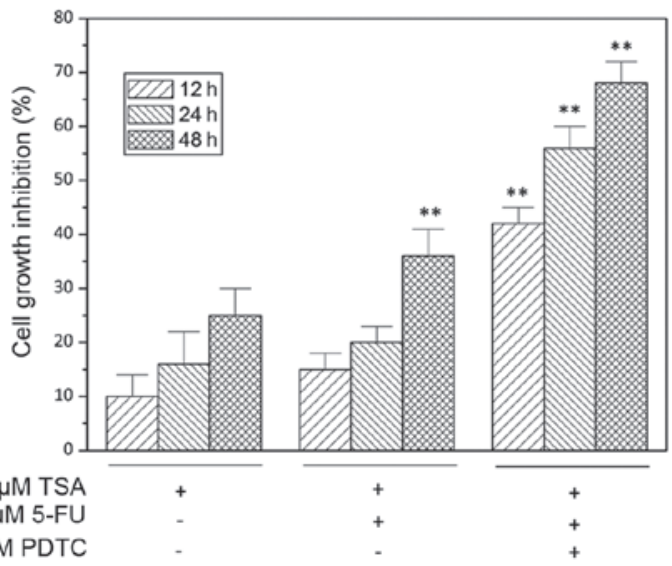

B

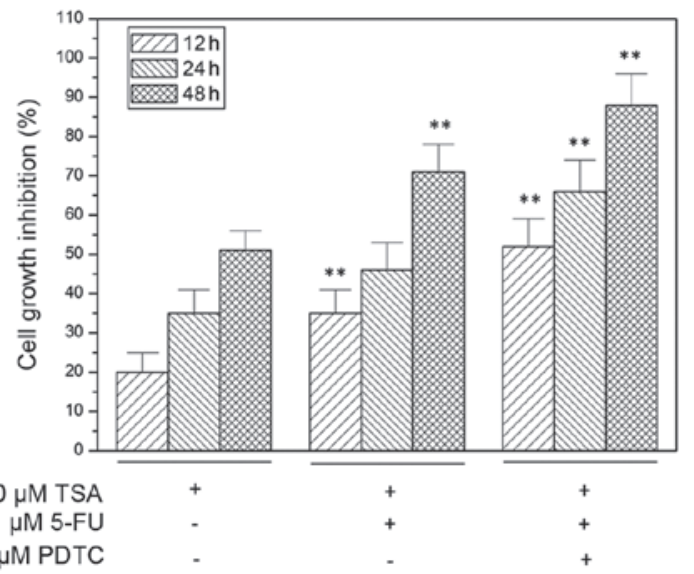

Figure 4. Nuclear factor- $\mathrm{kB}$ inhibitor, PDTC enhanced the effect of TSA-induced cell death on the (A) HCT1116 and (B) COLO205 colon cancer cell lines. Cultured cells were seeded in a 96-well plate at the density of $2 \times 10^{4}$ cells per well and treated by $20 \mu \mathrm{M}$ TSA, with or without $50 \mu \mathrm{M}$ PDTC. After 12,24 and $48 \mathrm{~h}$ of incubation, cell viability was determined using Cell Counting kit-8. Cell viability was expressed as a percentage of the control value. Data are presented as the mean \pm standard deviation of at least three independent experiments. ${ }^{* *} \mathrm{P}<0.05$ vs. TSA treatment. TSA, tanshinone IIA; 5-FU, fluorouracil; PDTC, pyrrolidine dithiocarbamate.

$N F-\kappa B$ inhibitor, pyrrolidine dithiocarbamate (PDTC), enhances TSA activity. As indicated in Fig. 4, the inhibition of NF- $\kappa$ B signaling with specific inhibitor PDTC significantly potentiated the suppression of TSA-induced cell growth in HCT1116 and COLO205 cells. Furthermore, the chemosensitizing effect of TSA on colon cancer cells was also enhanced 
by $50 \mu \mathrm{M}$ PDTC treatment $(\mathrm{P}<0.05)$, which is illustrated as increased cell growth inhibition in Fig. 4.

\section{Discussion}

Due to drug resistance and the toxic effect of current chemotherapy strategies, antitumor drug studies have been attempting to identify natural chemical compounds, and Chinese herbal medicine has been attracting increasing attention (36). TSA has been found to be an effective chemical component extracted from Danshen (Radix Salviae Miltiorrhizae) (37), which harbors anti-inflammatory and anti-oxidative activities (10-13). It has also been shown to have a cardioprotective effect by reducing apoptosis (38-40). Recently, an increasing number of studies has focused on the antitumor activity of TSA. For instance, Jung et al (41) and Liu et al (42) identified that TSA induced apoptosis in leukemic cells in vitro, possibly through the JAK/STAT3/5 and SHP1/2 pathways. In addition, Fu et al (25) found that TSA blocked the epithelial-mesenchymal transition through the downregulation of hypoxia-inducible factor- $1 \alpha$, reversing hypoxia-induced chemotherapy resistance in breast cancer cell lines. In addition, increasing evidence indicated that TSA can inhibit tumor cell growth and induce apoptosis $(15,17,43)$; however, despite the fact that in certain type of cancer evidence showed that intrinsic apoptosis pathways were involved $(14,44)$, the underlying mechanisms remain unclear. With regard to colon cancer, in 2008, Su et al identified that TSA inhibited cell growth and induced apoptosis in colon cancer cells (18). Shan et al (45) also indicated that TSA was able to inhibit colon cancer cell migration and invasion. Furthermore, in $2012 \mathrm{Su}$ et al (46) found that TSA potentiated the efficacy of 5 -FU in colon cancer cells in vivo through the downregulation of P-glycoprotein and LC3-II. The results of the present study confirmed the antitumor activity and chemosensitizing effect of TSA in colon cancer cells and provided new evidence that TSA can sensitize colon cancer cells to 5-FU through the suppression of $\mathrm{NF}-\kappa \mathrm{B}$ activation.

$\mathrm{NF}-\kappa \mathrm{B}$ is constitutively activated in numerous human cancer types $(30-32,35)$. The suppression of $\mathrm{NF}-\kappa \mathrm{B}$ may induce apoptosis and sensitize cancer cells to chemotherapy $(33,34,47,48)$. As an eukaryotic transcription factor, $N F-\kappa B$ regulates numerous genes that are differentially expressed and implicated in tumorigenesis, including c-Myc, COX-2 and matrix metalloproteinase-9 (49). In colon cancer, $\mathrm{NF}-\mathrm{\kappa B}$ activation participates in the promotion and progression of colon cancer (49); therefore, the aim of the present study was to investigate the effect of TSA on $\mathrm{NF}-\kappa \mathrm{B}$ activation and on $\mathrm{NF}-\kappa \mathrm{B}-$ regulated gene products. The results showed that TSA treatment decreased the level of the phosphorylated p65 in the nucleus of colon cancer cells and the NF- $\mathrm{BB}$-regulated gene expression levels of VEGF, COX-2, $\mathrm{c}-\mathrm{Myc}$ and $\mathrm{Bcl}-2$. In addition, the inhibition of NF- $\mathrm{NB}$ with specific inhibitor PDTC may further enhance the induction of cell death and the chemosensitizing effect of TSA in colon cancer cells.

In conclusion, the present study revealed that TSA was able to induce cell death in colon cancer cells and sensitize colon cancer cells to 5-FU therapy by inhibiting NF- $\mathrm{NB}$ activation; therefore, TSA appears to be a good option of adjuvant chemotherapy for colon cancer.

\section{References}

1. Siegel R, Naishadham D and Jemal A: Cancer statistics, 2012. CA Cancer J Clin 62: 10-29, 2012.

2. JinP, WuZT,LiSR,LiSJ, Wang JH,WangZH,Lu JG, Cui XJ,Han Y, Rao J and Sheng JQ: Colorectal cancer screening with fecal occult blood test: A 22-year cohort study. Oncol Lett 6: 576-582, 2013.

3. André T, Boni C, Mounedji-Boudiaf L, Navarro M, Tabernero J, Hickish T, Topham C, Zaninelli M, Clingan P, Bridgewater J, et al: Oxaliplatin, fluorouracil and leucovorin as adjuvant treatment for colon cancer. N Engl J Med 350: 2343-2351, 2004.

4. Verhoef MJ, Balneaves LG, Boon HS and Vroegindewey A: Reasons for and characteristics associated with complementary and alternative medicine use among adult cancer patients: A systematic review. Integr Cancer Ther 4: 274-286, 2005.

5. Boon Hand Wong J: Botanical medicine and cancer: A review of the safety and efficacy. Expert Opin Pharmacother 5: 2485-2501, 2004.

6. Fish JM, Welchons DR, Kim YS, Lee SH, Ho WK and Antzelevitch C: Dimethyl lithospermate b, an extract of danshen, suppresses arrhythmogenesis associated with the brugada syndrome. Circulation 113: 1393-1400, 2006.

7. Chang PN, Mao JC, Huang SH, Ning L, Wang ZJ, On T, Duan W and Zhu YZ: Analysis of cardioprotective effects using purified Salvia miltiorrhiza extract on isolated rat hearts. J Pharmacol Sci 101: 245-249, 2006.

8. Che AJ, Zhang JY, Li CH, Chen XF, Hu ZD and Chen XG: Separation and determination of active components in Radix Salviae miltiorrhizae and its medicinal preparations by nonaqueous capillary electrophoresis. J Sep Sci 27: 569-575, 2004.

9. Zhou L, Zuo Z and Chow MS: Danshen: An overview of its chemistry, pharmacology, pharmacokinetics and clinical use. J Clin Pharmacol 45: 1345-1359, 2005.

10. Jang SI, Kim HJ, Kim YJ, Jeong SI and You YO: Tanshinone IIA inhibits LPS-induced NF-kappaB activation in raw 264.7 cells: Possible involvement of the NIK-IKK, ERK1/2, P38 and JNK pathways. Eur J Pharmacol 542: 1-7, 2006.

11. Li W, Li J, Ashok M, Wu R, Chen D, Yang L, Yang H, Tracey KJ, Wang P, Sama AE and Wang H: A cardiovascular drug rescues mice from lethal sepsis by selectively attenuating a late-acting proinflammatory mediator, high mobility group box 1 . J Immunol 178: 3856-3864, 2007.

12. Lin R, Wang WR, Liu JT, Yang GD and Han CJ: Protective effect of tanshinone IIA on human umbilical vein endothelial cell injured by hydrogen peroxide and its mechanism. J Ethnopharmacol 108: 217-222, 2006

13. Wang AM, Sha SH, Lesniak W and Schacht J: Tanshinone (Salviae miltiorrhizae extract) preparations attenuate aminoglycoside-induced free radical formation in vitro and ototoxicity in vivo. Antimicrob Agents Chemother 47: 1836-1841, 2003.

14. Tian HL, Yu T, Xu NN, Feng C, Zhou LY, Luo HW, Chang DC, Le XF and Luo KQ: A novel compound modified from tanshinone inhibits tumor growth in vivo via activation of the intrinsic apoptotic pathway. Cancer Lett 297: 18-30, 2010.

15. Zhang J, Wang J, Jiang JY, Liu SD, Fu K and Liu HY: Tanshinone IIA induces cytochrome c-mediated caspase cascade apoptosis in A549 human lung cancer cells via the JNK pathway. Int J Oncol 45: 683-690, 2014.

16. Yun SM, Jung JH, Jeong SJ, Sohn EJ, Kim B and Kim SH: Tanshinone IIA induces autophagic cell death via activation of AMPK and ERK and inhibition of mTOR and p70 S6k in KBM-5 leukemia cells. Phytother Res 28: 458-464, 2014.

17. Yang L, Guo H, Dong L, Wang L, Liu C and Wang X: Tanshinone IIA inhibits the growth, attenuates the stemness and induces the apoptosis of human glioma stem cells. Oncol Rep 32: 1303-1311, 2014

18. Su CC, Chen GW, Kang JC and Chan MH: Growth inhibition and apoptosis induction by tanshinone IIA in human colon adenocarcinoma cells. Planta Med 74: 1357-1362, 2008.

19. Luo P, Tan Z, Zhang Z, Li H and Mo Z: Inhibitory effects of salvianolic acid $B$ on the high glucose-induced mesangial proliferation via NF-kappaB-dependent pathway. Biol Pharm Bull 31: 1381-1386, 2008.

20. Lui VW, Boehm AL, Koppikar P, Leeman RJ, Johnson D, Ogagan M, Childs E, Freilino M and Grandis JR: Antiproliferative mechanisms of a transcription factor decoy targeting signal transducer and activator of transcription (stat) 3: The role of stat 1 . Mol Pharmacol 71: 1435-1443, 2007. 
21. Chen SJ: A potential target of Tanshinone IIA for acute promyelocytic leukemia revealed by inverse docking and drug repurposing. Asian Pac J Cancer Prev 15: 4301-4305, 2014.

22. Chiu SC, Huang SY, Chen SP, Su CC, Chiu TL and Pang CY: Tanshinone IIA inhibits human prostate cancer cells growth by induction of endoplasmic reticulum stress in vitro and in vivo. Prostate Cancer Prostatic Dis 16: 315-322, 2013.

23. Won SH, Lee HJ, Jeong SJ, Lü J and Kim SH: Activation of p53 signaling and inhibition of androgen receptor mediate tanshinone IIA induced G1 arrest in LNCaP prostate cancer cells. Phytother Res 26: 669-674, 2012.

24. Kan S, Cheung WM, Zhou Y and Ho WS: Enhancement of doxorubicin cytotoxicity by tanshinone IIA in HepG2 human hepatoma cells. Planta Med 80: 70-76, 2014

25. Fu P, Du F, Chen W, Yao M, Lv K and Liu Y: Tanshinone IIA blocks epithelial-mesenchymal transition through HIF-1 $\alpha$ downregulation, reversing hypoxia-induced chemotherapy resistance in breast cancer cell lines. Oncol Rep 31: 2561-2568, 2014.

26. Housman G, Byler S, Heerboth S, Lapinska K, Longacre M, Snyder N and Sarkar S: Drug resistance in cancer: An overview. Cancers (Basel) 6: 1769-1792, 2014.

27. Garg A and Aggarwal BB: Nuclear transcription factor-kappaB as a target for cancer drug development. Leukemia 16: 1053-1068, 2002.

28. Yu HG, Yu LL, Yang Y, Luo HS, Yu JP, Meier JJ, Schrader H, Bastian A, Schmidt WE and Schmitz F: Increased expression of RelA/nuclear factor-kappa B protein correlates with colorectal tumorigenesis. Oncology 65: 37-45, 2003.

29. Liptay S, Weber CK, Ludwig L, Wagner M, Adler G and Schmid RM Mitogenic and antiapoptotic role of constitutive NF-kappaB/Re activity in pancreatic cancer. Int J Cancer 105: 735-746, 2003.

30. Nair A, Venkatraman M, Maliekal TT, Nair B and Karunagaran D $\mathrm{Nf}-\mathrm{kappaB}$ is constitutively activated in high-grade squamous intraepithelial lesions and squamous cell carcinomas of the human uterine cervix. Oncogene 22: 50-58, 2003.

31. Li W, Tan D, Zenali MJ and Brown RE: Constitutive activation of nuclear factor-kappa $\mathrm{B}(\mathrm{NF}-\kappa \mathrm{B})$ signaling pathway in fibrolamellar hepatocellular carcinoma. Int J Clin Exp Pathol 3: 238-243, 2010.

32. Nagel D, Vincendeau M, Eitelhuber AC and Krappmann D: Mechanisms and consequences of constitutive nf-kappab activation in B-cell lymphoid malignancies. Oncogene 11: 5655-5565, 2014.

33. Shishodia S, Amin HM, Lai R and Aggarwal BB: Curcumin (diferuloylmethane) inhibits constitutive NF-kappaB activation, induces G1/s arrest, suppresses proliferation and induces apoptosis in mantle cell lymphoma. Biochem Pharmacol 70: 700-713, 2005.

34. Baldwin AS: Control of oncogenesis and cancer therapy resistance by the transcription factor NF-kappaB. J Clin Invest 107: 241-246, 2001.

35. Shen HM and Tergaonkar V: NFkappaB signaling in carcinogenesis and as a potential molecular target for cancer therapy. Apoptosis 14 348-363, 2009

36. Li X, Yang G, Li X, Zhang Y, Yang J, Chang J, Sun X, Zhou X, Guo Y, Xu Y, et al: Traditional Chinese medicine in cancer care: A review of controlled clinical studies published in chinese. PloS One 8: e60338, 2013
37. Shang Q, Xu H and Huang L: Tanshinone IIA: A promising natural cardioprotective agent. Evid Based Complement Alternat Med 2012: 716459, 2012.

38. Jiang FL, Leo S, Wang XG, Li H, Gong LY, Kuang Y and Xu XF: Effect of tanshinone IIA on cardiomyocyte hypertrophy and apoptosis in spontaneously hypertensive rats. Exp Ther Med 6: 1517-1521, 2013.

39. Jin HJ and Li CG: Tanshinone IIA and cryptotanshinone prevent mitochondrial dysfunction in hypoxia-induced H9c2 cells: Association to mitochondrial ROS, intracellular nitric oxide and calcium levels. Evid Based Complement Alternat Med 2013: 610694, 2013.

40. Jin HJ, Xie XL, Ye JM and Li CG: Tanshinoneiia and cryptotanshinone protect against hypoxia-induced mitochondrial apoptosis in H9c2 cells. PLoS One 8: e51720, 2013.

41. Jung JH, Kwon TR, Jeong SJ, Kim EO, Sohn EJ, Yun M and Kim SH: Apoptosis induced by tanshinone IIA and cryptotanshinone is mediated by distinct JAK/STAT3/5 and SHP1/2 signaling in chronic myeloid leukemia K562 cells. Evid Based Complement Alternat Med 2013: 805639, 2013.

42. Liu JJ, Lin DJ, Liu PQ, Huang M, Li XD and Huang RW: Induction of apoptosis and inhibition of cell adhesive and invasive effects by tanshinone IIA in acute promyelocytic leukemia cells in vitro. J Biomed Sci 13: 813-823, 2006.

43. Wang JF, Feng JG, Han J, Zhang BB and Mao WM: The molecular mechanisms of tanshinone IIA on the apoptosis and arrest of human esophageal carcinoma cells. Biomed Res Int 2014: 582730, 2014

44. Tseng PY, Lu WC, Hsieh MJ, Chien SY and Chen MK: Tanshinone IIA induces apoptosis in human oral cancer KB cells through a mitochondria-dependent pathway. Biomed Res Int 2014: 540516, 2014

45. Shan YF, Shen X, Xie YK, Chen JC, Shi HQ, Yu ZP, Song QT, Zhou MT and Zhang QY: Inhibitory effects of tanshinone II-a on invasion and metastasis of human colon carcinoma cells. Acta Pharmacol Sin 30: 1537-1542, 2009.

46. Su CC: Tanshinone IIA potentiates the efficacy of 5-FU in colo205 colon cancer cells in vivo through downregulation of P-gp and LC3-II. Exp Ther Med 3: 555-559, 2012.

47. Hernandez-Flores G, Ortiz-Lazareno PC, Lerma-Diaz JM, Dominguez-Rodriguez JR, Jave-Suarez LF, Aguilar-Lemarroy Adel C, de Celis-Carrillo R, del Toro-Arreola S, Castellanos-Esparza YC and Bravo-Cuellar A: Pentoxifylline sensitizes human cervical tumor cells to cisplatin-induced apoptosis by suppressing nf-kappa B and decreased cell senescence. BMC Cancer 11: 483, 2011.

48. Liu T, Liu D, Liu J, Song JT, Gao SL, Li H, Hu LH and Liu BR: Effect of NF- $\kappa \mathrm{B}$ inhibitors on the chemotherapy-induced apoptosis of the colon cancer cell line HT-29. Exp Ther Med 4: 716-722, 2012 .

49. Wang S, Liu Z, Wang L and Zhang X: NF-kappaB signaling pathway, inflammation and colorectal cancer. Cell Mol Immunol 6: 327-334, 2009. 